\title{
Effects of Laser Cleaning on Chemical Composition of Mortar Surfaces
}

\author{
A.J. Klemm* and P. Sanjeevan
}

School of Built and Natural Environment, Glasgow Caledonian University, UK

\begin{abstract}
The paper presents a part of the larger study on microstructural features of mortars and their effects on laser cleaning process. It focuses on presenting the results of investigation on the influence of laser cleaning on chemical composition of mortar surfaces. The experimental results prove that the laser cleaning process leads to an increase of Si element concentration and/or decrease in Ca concentration. The observed alterations should be associated with changes in the relative distribution of melted cement paste and aggregate and therefore relative elemental abundance in the near-surface layer. Furthermore, curing and service conditions of mortars seem to have strong influence on laser cleaning process and therefore on surface quality. Exposure to freezing/thawing cycles and subsequent surface damage facilitates deeper penetration of paint and consequently affects the efficiency of cleaning. The amount of residual carbon on F/T samples tested in the course of this study was around $42 \%$ higher than on the surfaces of laboratory-cured samples.
\end{abstract}

\section{INTRODUCTION}

During the last couple of decades laser processing of cementitious materials, such as surface glazing, scabbing or removal of contaminants has been gradually becoming more and more popular.

The modern theory of light began in the 1700s with the work of Isaac Newton. However, the most important theory concerning emission and absorption of light was first proposed by Albert Einstein in 1917. These ideas provided the basis for lasers development. Since 1960 this development has been extremely rapid and the unique properties of lasers have led to different applications in a wide range of fields in industry (drilling, cleaning, cutting, and welding), in medicine (ophthalmology and dermatology) as well as in surveying and military applications [1]. Surface cleaning by laser radiation is one of these applications. It involves complex mechanisms, including the photo-thermal, photochemical, and photomechanical processes. The predominant mechanism depends on laser beam parameters as well as physical, chemical, thermal, and optical properties of surfaces. The relationship between laser cleaning processes and substrate parameters is a two-way relationship. The great variation in absorptivity of highly developed surfaces of cementitious materials results in substantial differences in their responses to laser irradiation. The laser cleaning process is unarguably associated with some moderations of mortar's geometrical microstructure and chemical composition. Since high temperature is involved in the laser cleaning process, the chemical composition of surface may change, followed by crack development and subsequent alteration of roughness [2-4]. Despite the fact that these effects are generally microscopic and only visible at high magnification, their importance should not be underestimated as they may expose surfaces to further accelerated environmental deterio-

*Address correspondence to this author at the School of Built and Natural Environment, Glasgow Caledonian University, UK; Tel: +44 1413313892; Fax: +44 1413313696; E-mail: a.klemm@gcal.ac.uk ration. Lack of comprehensive knowledge of the effects of substrate parameters of cementitious materials during the laser cleaning process is one of the restrains still to be address Sanjeevan $[5,6]$.

Ordinary Portland Cement concrete contains on average $70 \%$ of C-S-H gel, $20 \%$ of well-crystallised $\mathrm{Ca}(\mathrm{OH})_{2}$, ettringite $\left(\mathrm{C}_{6} \mathrm{AS}_{3} \mathrm{H}_{32}\right)$, calcium aluminate monosulfate hydrate $\left(\mathrm{C}_{4} \mathrm{ASH}_{18}\right)$ and some minor phases.

Table 1. The Temperature Regions in Which Damage Occurs (Schmidt JMPT 2003) [7]

\begin{tabular}{|c|c|}
\hline Temperature Range & Effect \\
\hline \hline Up to $400^{\circ} \mathrm{C}$ & $\begin{array}{c}\text { Loss of physically bond water from } \\
\text { pores and gel }\end{array}$ \\
\hline $400-540^{\circ} \mathrm{C}$ & Dehydration of $\mathrm{Ca}(\mathrm{OH})_{2}$ \\
\hline $570-573^{\circ} \mathrm{C}$ & Conversion of quartz from $\alpha$ to $\beta$ phase \\
\hline $600-700^{\circ} \mathrm{C}$ and above & Decomposition of C-S-H* ${ }^{*}$ \\
\hline $800^{\circ} \mathrm{C}$ and above & Decarbonation of $\mathrm{CaCO}_{3}$ \\
\hline $1150-1200^{\circ} \mathrm{C}$ & Melting \\
\hline
\end{tabular}

*C-S-H means amorphous calcium silicate hydrates.

Its dehydration starts when the surface is heated for considerable time and water is lost at $200^{\circ} \mathrm{C}$. Table $\mathbf{1}$ above presents the physical and chemical changes occurring during the heating up of concrete.

In the case of instant exposure, generation of high internal steam pressure and increase of tensile stresses leads to extensive spalling. It can manifest itself as explosive spalling (series of pop-outs) or sloughing off concrete surface (gradual non-violent separation of the concrete) and often occurs near the critical point of steam $\left(374^{\circ} \mathrm{C}\right)$. Above this point, pores cannot contain liquid and vapour together, and pressures increase considerably. Sudden vaporization and ejection of surface material forms plasma as shown Fig. (1). 


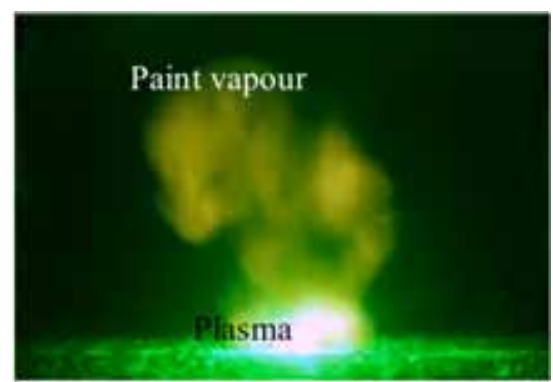

Fig. (1). Plasma patch.

Thermal stresses sufficient for disintegration can be unloaded by formation of thermal cracks (Georgali CCC 2005) [8].

Rapid temperature increase during laser exposure may lead also to noticeable modification of surface chemical composition. Changes in the composition of cementitious surfaces may be associated with the following processes:

- Dehydration starting as soon as surface gets heated, and water loss at $200^{\circ} \mathrm{C}$. The dehydration of $\mathrm{Ca}(\mathrm{OH})_{2}$ follows shortly after $420^{\circ} \mathrm{C}$ is reached and is represented by the following equation: $\mathrm{Ca}(\mathrm{OH})_{2} \rightarrow \mathrm{CaO}+\mathrm{H}_{2} \mathrm{O}$

- Breakdown of hydrated chemical bonds starting at around $550^{\circ} \mathrm{C}$ with a complete break down at $800-900^{\circ} \mathrm{C}$. Decarboxylation of $\mathrm{Ca}_{2} \mathrm{CO}_{3}$ occurring at around $700^{\circ} \mathrm{C}$.

- Creation of stable ceramic bond (glazing) such as $\mathrm{CaO} \cdot \mathrm{SiO}_{2}, 2 \mathrm{CaO} \cdot \mathrm{SiO}_{2}$, anorthite $\left(\mathrm{CaO} \cdot \mathrm{Al}_{2} \mathrm{O}_{3} \cdot 2 \mathrm{SiO}_{2}\right)$, and rankinite $\left(3 \mathrm{CaO} \cdot 2 \mathrm{SiO}_{2}\right)$ starting at around $1600^{\circ} \mathrm{C}$ [9].

This paper focuses on the effects of laser cleaning process on chemical composition of mortar surfaces exposed to laboratory conditions and alternated freezing and thawing cycles.

\section{EXPERIMENTAL DETAILS}

Samples subjected to the analysis differ in their microstructure (HP - high porosity; LP - low porosity, F/T frost damaged) and moisture content (WET/DRY). Mortar specimens had cement/sand ratio of $1: 1$, water/cement ratio 0.4 and different air-entraining admixture content. The mix proportions, mechanical and physical properties of the mortar samples are shown in Table 2, below.

All samples were cured one day in the prismatic moulds and seven days in water. Two sets were then further cured for 6 months under a polythene cover before being painted with a black colour spray paint. The third set of samples was subjected to 600 alternated freezing and thawing conditions in a fully automated climate control chamber and subsequently painted. The cooling rate was set at $1^{\circ} \mathrm{C} / \mathrm{min}$ and the temperature varied from $-20^{\circ} \mathrm{C}$ to $+20^{\circ} \mathrm{C}$. Each cycle consisted of three hours freezing phase and equally long thawing period [10].

Surface roughness was measured by a stylus device and represented by average surface roughness $(\mathrm{Ra}) .50$ points per sample were measured to find the $95 \%$ confidential interval of the surface roughness.

Cleaning of graffiti was performed by Nd:YAG laser with the following characteristics: wavelength: $1.06 \mu \mathrm{m}$, energy: $500 \mathrm{~mJ}$, pulse duration: $10 \mathrm{~ns}$ and pulse repetition rate: 1 Hz. Fig. (2) shows the experimental setup used in this investigation.

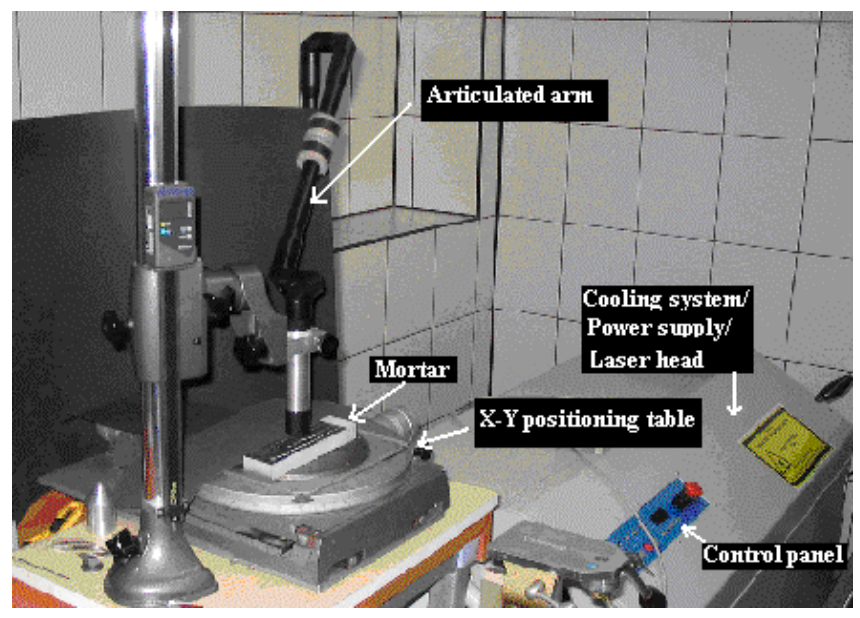

Fig. (2). Experimental setup.

Dry and wet mortar samples were subjected to laser radiation of the same laser fluence $3.06 \mathrm{~J} / \mathrm{cm}^{2}$. DRY samples were in equilibrium with surrounding air in a laboratory (temperature of $23 \pm 0.5^{\circ} \mathrm{C}$ and $\mathrm{RH}$ of $50 \pm 5 \%$ ). WET samples were immersed in water for 24 hours to reach full saturation. All samples have been examined by the Environmental Scanning Electron microscopy (ZEISS EVO 60) and the Energy Dispersive X-Ray.

Table 2. Compositions, Mechanical Properties, Surface Roughness and Moisture Content of the Mortar Samples

\begin{tabular}{|c|c|c|c|c|c|c|c|c|}
\hline \multirow[b]{2}{*}{ Mix } & \multirow{2}{*}{ 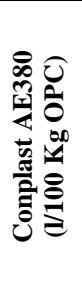 } & \multirow{2}{*}{ 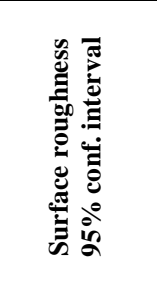 } & \multirow{2}{*}{ 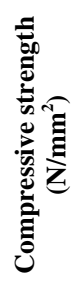 } & \multirow{2}{*}{ 泀 } & \multirow{2}{*}{ 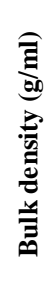 } & \multirow{2}{*}{ 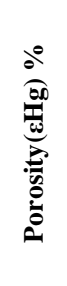 } & \multicolumn{2}{|c|}{ Moisture content } \\
\hline & & & & & & & $\frac{\partial}{a}$ & $\stackrel{5}{3}$ \\
\hline LP-C & 0 & $15.58-17.89$ & 79.4 & 8.3 & 2.1 & 11.9 & 2.3 & 8.2 \\
\hline HP-C & 1.3 & $15.58-17.89$ & 57.5 & 7.4 & 1.8 & 26.4 & 3.2 & 10.7 \\
\hline FT-C ${ }^{0}$ & 0 & $15.79-18.13$ & 76.2 & 8.1 & 2.1 & 12.4 & 4.2 & 10.9 \\
\hline
\end{tabular}




\section{RESULTS AND DISCUSSION}

Sudden temperature increase on surfaces resulted in their significant alterations. Optical micrographs and BSE images of laser-cleaned areas, seen in Fig. (3), clearly show two zones - undamaged and damaged with the characteristic glassy patches.

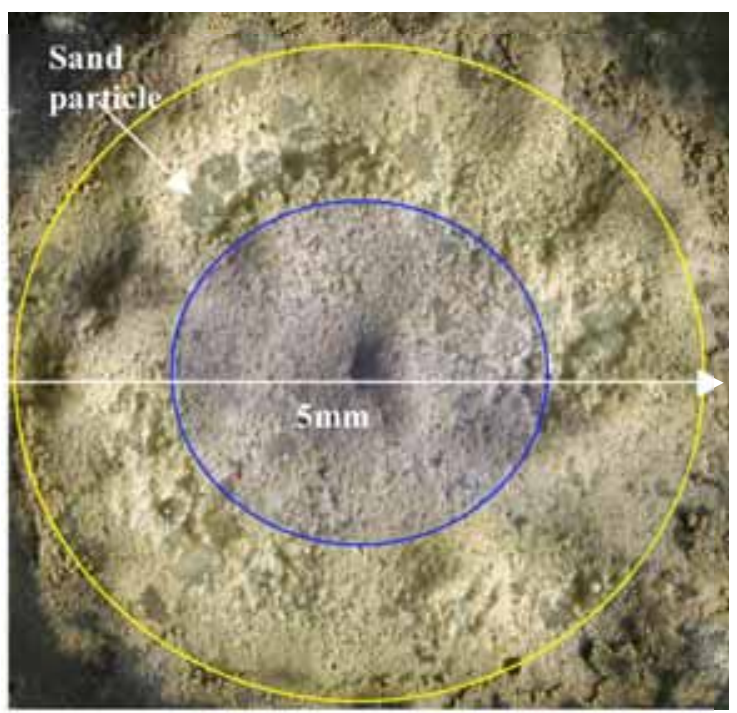

Fig. (3). Optical micrograph of laser-cleaned area (LP-C(WET)) (80x).

It should be stressed that the effect of laser radiation on deeper layers was insignificant. Temperature increase recorded by thermocouples positioned $2 \mathrm{~mm}$ below the surface did not exceed 7 deg $\mathrm{C}$ as presented in Fig. (4). Porosity and presence of water proved to have a small effect on temperature field. Wet and low porosity mortars experienced 10 per cent lower temperature increase.

Chemical analysis of mortars were focused on main elements of cementitious composites: $\mathrm{Ca}, \mathrm{Si}, \mathrm{Al}, \mathrm{Fe}$, and $\mathrm{S}$. Fig. (5) shows EDX spectra for different points marked in BSE image of laser- cleaned area. The points for chemical analysis were selected on the cement paste surface excluding sand particles. Points 'A' and 'B' represent the undamaged laser cleaned area whereas points ' $C$ ' and ' $D$ ' represent damaged zone.

In the case of sample LP-C(WET), the average values of $\mathrm{Ca} / \mathrm{Si}$ corresponding to the damaged and undamaged zones were found to be 1.54 and 2.26 respectively. The average value of $\mathrm{Ca} / \mathrm{Si}$ corresponding to the reference mortar was 3.61, indicating higher concentration of $\mathrm{Si}$ in the lasercleaned area. Moreover, the amount of $\mathrm{Si}$ in the damaged zone was higher than in the undamaged zone. Changes in concentration of $\mathrm{Al}, \mathrm{Fe}$, and $\mathrm{S}$, on mortar surfaces seem to have been insignificant (Table $\mathbf{3}$ ).

Similar analyses were performed for remaining mortar surfaces. Fig. (7) shows the value of $\mathrm{Ca} / \mathrm{Si}$ ratio before and after laser cleaning for different mortar samples. 'Mortar surface' refers to the surface before laser cleaning while 'undamaged and damaged area' to the surface after cleaning. All samples showed the similar pattern, irrespective of the sur-
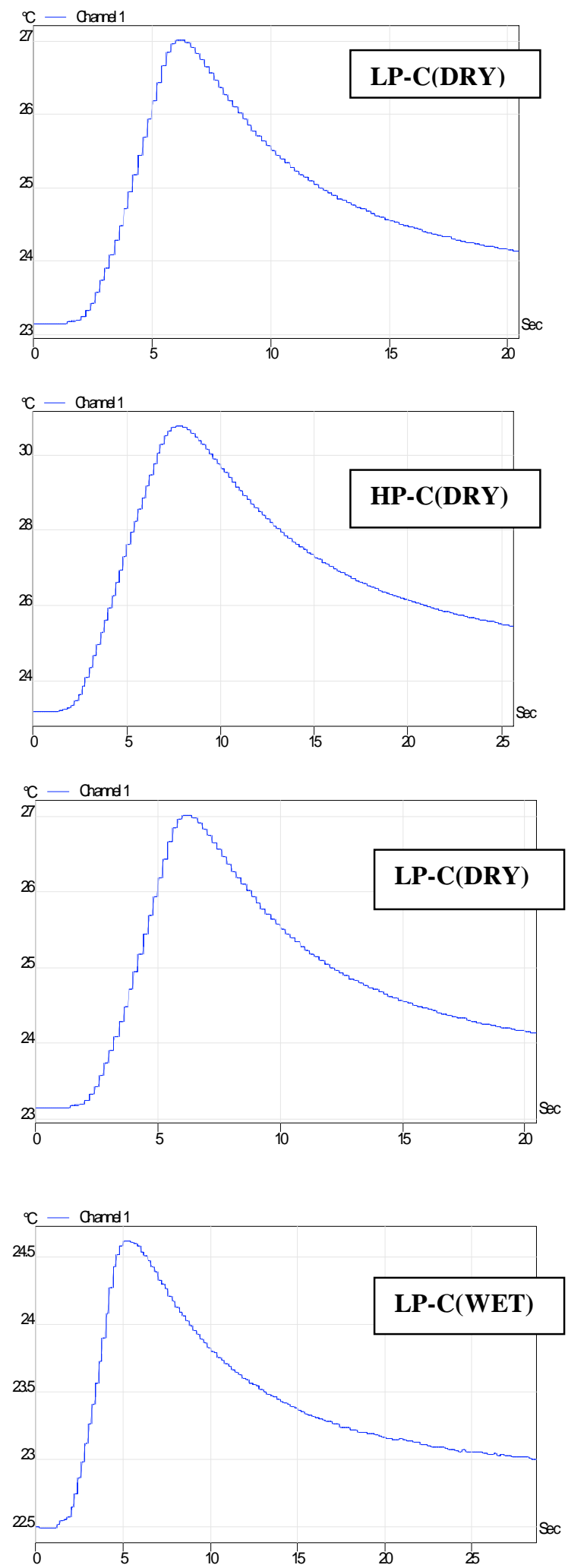

Fig. (4). Temperature increase during laser cleaning $-2 \mathrm{~mm}$ below surface.

face condition. The $\mathrm{Ca} / \mathrm{Si}$ value in the laser-cleaned areas was always found to be higher than on the reference surface. Moreover, the value of $\mathrm{Ca} / \mathrm{Si}$ obtained from the damaged zone was higher than from the undamaged zone. Moreover, 
Table 3. Elements with Respect to Different Points on the Laser Cleaned Area; LP-C(WET)

\begin{tabular}{|c|c|c|c|c|}
\hline \multicolumn{5}{|c|}{ LP-C(WET)(Atomic \%) } \\
\hline Element & A & B & C & D \\
\hline \hline $\mathrm{O} / \mathrm{Si}$ & 21.19 & 23.38 & 17.08 & 14.67 \\
\hline $\mathrm{C} / \mathrm{Si}$ & 26.40 & 31.83 & 15.09 & 10.84 \\
\hline $\mathrm{Al} / \mathrm{Si}$ & 0.41 & 0.48 & 0.51 & 0.65 \\
\hline $\mathrm{S} / \mathrm{Si}$ & 0.11 & 0.11 & 0.14 & 0.06 \\
\hline $\mathrm{Ca} / \mathrm{Si}$ & 2.26 & 2.09 & 1.75 & 1.54 \\
\hline $\mathrm{Fe} / \mathrm{Si}$ & 0.15 & 0.13 & 0.07 & 0.11 \\
\hline
\end{tabular}
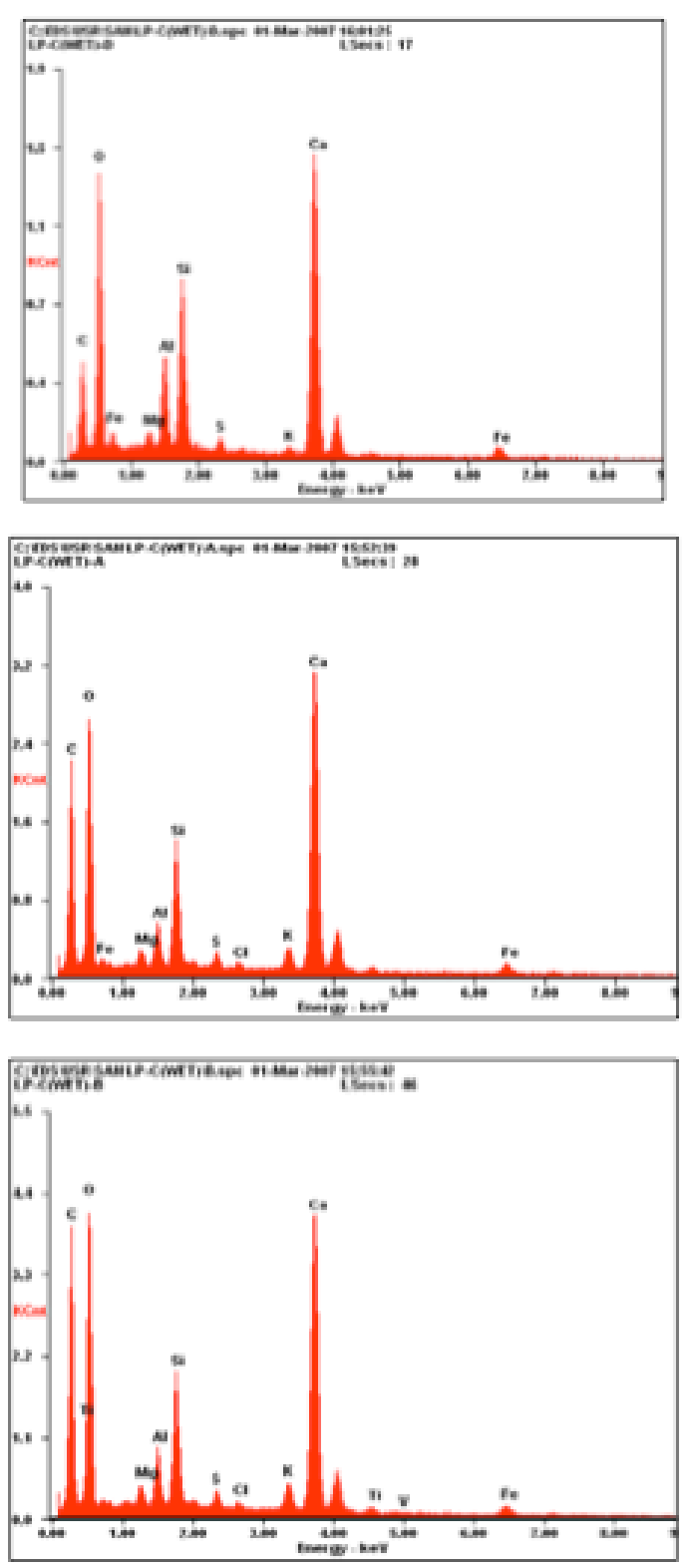

Fig. (5). EDX spectra of LP-C(WET).

the amount of $\mathrm{Si}$ in the damaged zone was higher than in the undamaged zone. Changes in concentration of other elements, such as $\mathrm{Al}, \mathrm{Fe}$, and $\mathrm{S}$, on mortar surfaces seem to have been insignificant.
Increase in $\mathrm{Si}$ content with respect to $\mathrm{Ca}$ on the mortar surfaces may be explained by three mechanisms:

- At very high temperatures, melted cement paste (high Calcium content) and aggregate (high Silicon content) may change their own relative distribution by flowing around and thus changing their relative elemental abundance near surface [11].

- Reduction in $\mathrm{Ca}$ on the laser-processed mortar surfaces due to removal of $\mathrm{CaCO}_{3}$ may result in lowering $\mathrm{Ca} / \mathrm{Si}$ value [12].

- The melting point of $\mathrm{SiO}_{2}$, and $\mathrm{CaO}$ are around $1600^{\circ} \mathrm{C}$ and $2570^{\circ} \mathrm{C}$ respectively. Thus, when the temperature of mortar is in between $1600^{\circ} \mathrm{C}$ and $2570^{\circ} \mathrm{C}, \mathrm{SiO}_{2}$ becomes liquid and $\mathrm{CaO}$ remains solid. Since density of solid $\mathrm{SiO}_{2}$ and solid $\mathrm{CaO}$ are around $2200 \mathrm{~kg} / \mathrm{m}^{3}$ and $3350 \mathrm{~kg} / \mathrm{m}^{3} \mathrm{re}-$ spectively, $\mathrm{SiO}_{2}$ may migrate towards the near surface as shown in Fig. (6a). When the temperature of mortar surface exceeds $2570^{\circ} \mathrm{C}$ both $\mathrm{CaO}$ and $\mathrm{SiO}_{2}$ become liquid. Density of $\mathrm{SiO}_{2}$ is lower than the density of the $\mathrm{CaO}$ and therefore $\mathrm{SiO}_{2}$ has a tendency to move towards the surface as shown in Fig. (6b).

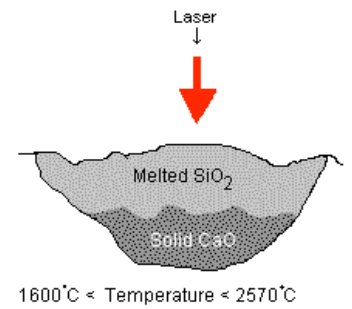

(a)

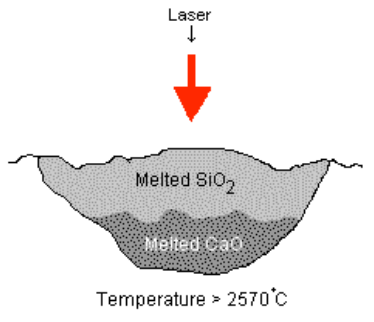

(b)
Fig. (6). Movement of $\mathrm{SiO}_{2}$ towards a mortar surface caused by laser .

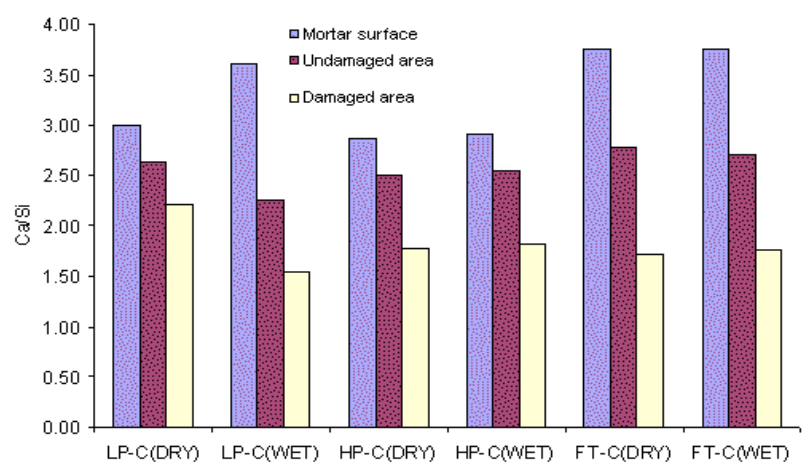

Fig. (7). The value of $\mathrm{Ca} / \mathrm{Si}$ ratio on surfaces of mortar samples.

EDX analyses of original mortar surfaces, painted surfaces and laser-cleaned areas are shown in Fig. (8). Carbon was the main feature of the EDX spectrum of the painted surfaces (Fig. 8b). The amount of carbon on the painted mortar surfaces was higher than on laser-cleaned areas or on reference surfaces. Disappearance of some carbon from the painted surface, caused by laser interaction, may represent the effectiveness of laser cleaning. Higher carbon concentration on laser-cleaned areas, compared to reference surfaces, may indicate some residual paint. 


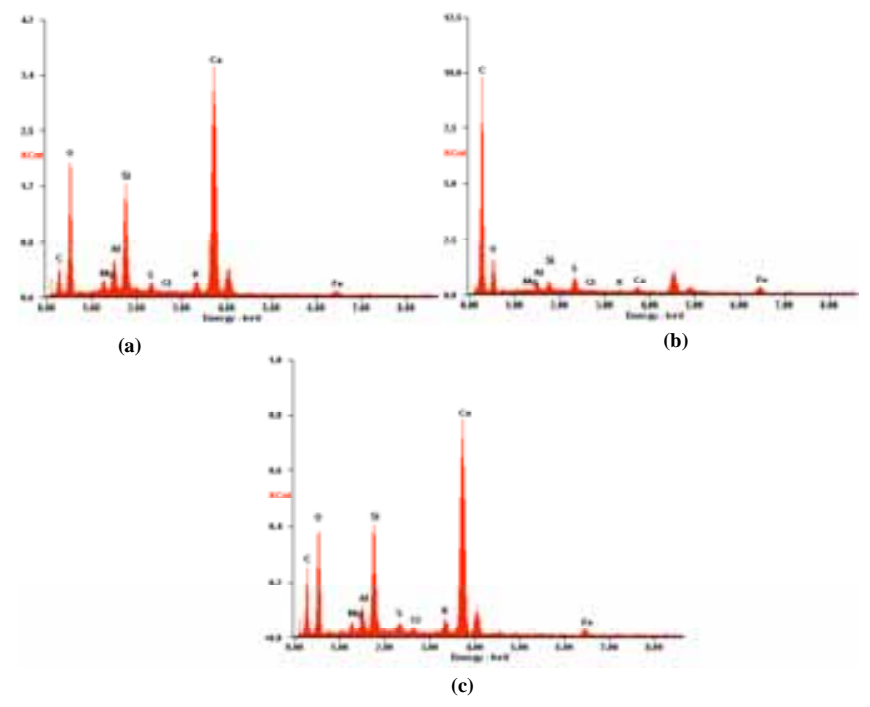

Fig. (8). EDX spectra of a mortar surfaces (HP-C(WET)) a) Reference mortar surface before the painting; b) Painted mortar surface; c) Laser-cleaned area.

Fig. (9) shows the amount of carbon on the painted surface, reference mortar surface, and laser-cleaned area, with respect to different surface conditions. The painted surface contained around $77 \%$ of carbon, while the plain mortar surfaces had only $24-34 \%$ of carbon.

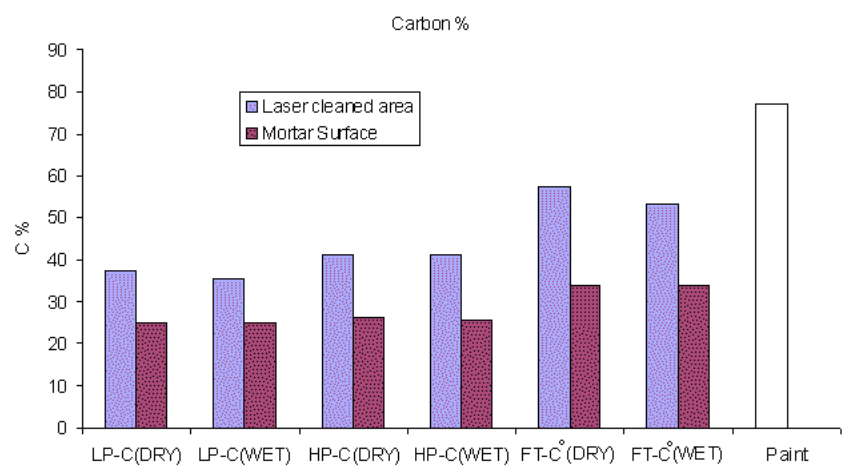

Fig. (9). Amount of carbon on the laser-cleaned area and reference mortar surface.

Curing condition and near-surface porosity seem to have some influence on the amount of residual paint on lasercleaned surfaces. In the case of mortar samples exposed to 600 freeze/thaw cycles, the amount of carbon on the lasercleaned areas was around $42 \%$ higher than on the laboratorycured samples. The BSE images of mortar subjected to frost attack (Fig. 10) indicate the presence of a higher number pores on the mortar surface than on laboratory-cured mortar samples.

The higher near-surface porosity of mortar could enhance the penetration of paint into the mortar. Laser cleaning of samples exposed to 600 freeze/thaw cycles, may therefore be more problematic. Furthermore, the amount of carbon after laser cleaning of the laboratory-cured high porosity samples was around $14 \%$ higher than for the laboratory-cured low
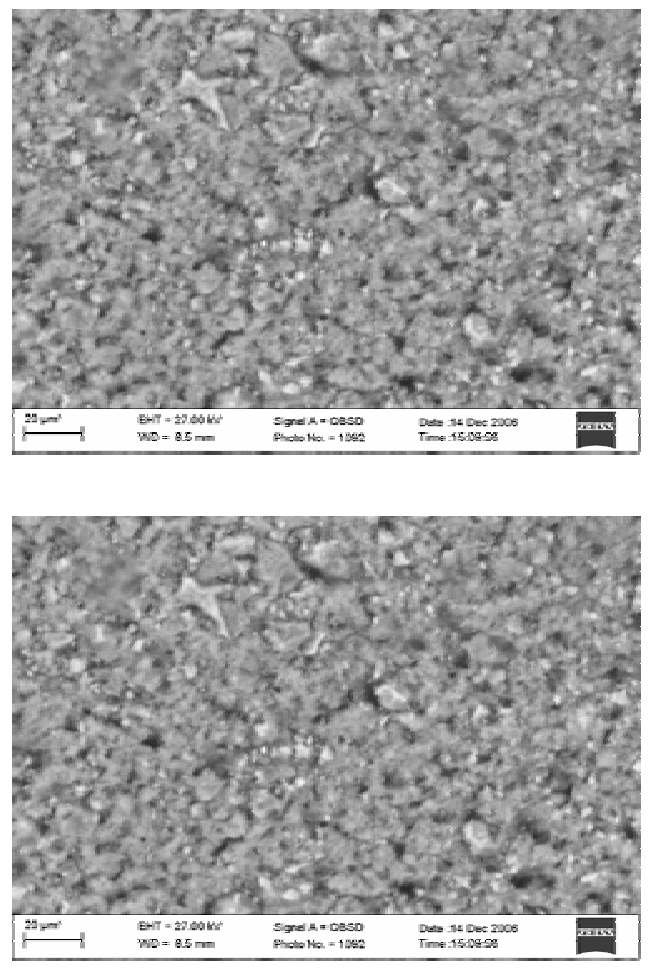

(b)

Fig. (10). BSE images of mortar (1000x):

a) $\quad \mathrm{FT}-\mathrm{C}^{0}(\mathrm{DRY})$; more porous surface;

b) LP-C(DRY); more solid and dense surface

porosity mortar samples. This indicates that laser cleaning of highly porous samples is more difficult than the low porous sample. As a whole, the average amount of carbon on the laser-cleaned areas was around $56 \%$ more than on unpainted mortar surfaces.

It has to be noted that the EDX method, although widely accepted for characterisation of materials' chemical composition, may provide results difficult to be analysed, particularly in cementitious materials. Non-uniformity of a matrix and differences in hydration rates of cement may lead to significant variations in the relative concentration of individual elements at different locations.

\section{CONCLUSIONS}

The laser cleaning process is associated with some moderations of mortar's chemical composition. Since high temperature is involved in the laser cleaning process, the chemical composition of near surface layer may change. Lasercleaned surfaces exhibit a high concentration of Si element and/or low concentration in Ca element, compared with the original mortar surface. The value of $\mathrm{Ca} / \mathrm{Si}$ on laser-cleaned areas is around $50 \%$ lower than on the reference surfaces, most probably due to changes in the relative distribution of melted cement paste and aggregate and therefore relative elemental abundance in the near-surface layer. Lower values of the $\mathrm{Ca} / \mathrm{Si}$ ratio could also be attributed to the removal of $\mathrm{CaCO}_{3}$ or movement of $\mathrm{SiO}_{2}$ to mortar surfaces. Variations of other elements, such as $\mathrm{Al}, \mathrm{Fe}$, and $\mathrm{S}$, seem to be insignificant.

Furthermore, higher concentration of Carbon (the main element of paint) in the laser-cleaned area proved that the 
removal of paint is always associated with some modification of mortars.

Curing regime proved to have a strong influence on lasercleaning process. Formation of pores and microcracks on samples exposed to freezing/thawing cycles makes the mortar surface more sensitive to laser radiation. Lower tensile strength of samples exposed to freezing/thawing cycles leads to an inevitable removal of mortar. The amount of residual carbon on these samples was around $42 \%$ higher than on the surfaces of laboratory-cured samples, due to deeper penetration of paint facilitated by the deteriorated F/T surface.

It should be noted that further research is essential to validate above results and quantitatively explain the phenomena.

\section{REFERENCES}

[1] M. Cooper, Laser cleaning in conservation, an introduction. Oxford, Butterworth-Heinemann, 1998.

[2] L. Li, W.M. Steen, P.J. Modern, J.T. Spencer, Laser removal of surface embedded contaminations on/in building structures. Laser Materials Processing and Machining, SPIE: 2246, 1994.

[3] J. Lawrence and L. Li "The effects of process gas type on the surface condition of high-power diode laser-treated ordinary Portland cement". Optics and Lasers in Engineering 36: pp. 599-605, 2001.

[4] I. Matsui, K. Nagai, N. Yuasa, Y. Ishigami, Removing graffiti on concrete surface by laser. Nihon University, Taisei corporation Ja- pan, Proceeding of the International Congress "Challenges in Concrete Construction" held at the University of Dundee, Scotland, UK, 2002.

[5] P. Sanjeevan, A.J. Klemm and P. Klemm, Removal of graffiti from the mortar by using Q-switched Nd:YAG laser, Applied Surface Science, vol. 253 (20), pp. 8543-8553, 2007.

[6] P. Sanjeevan, A.J. Klemm and P. Klemm, The effects of microstructural features of mortars on the laser cleaning process, 8th International Symposium "Brittle Matrix Composites", 2006, Warsaw, Poland.

[7] M.J.J. Schmidt, L. Li and J.T. Spencer, "An investigation into the feasibility and characteristics of using a $2.5 \mathrm{k} \mathrm{W}$ high power diode laser for paint stripping". Journal of Materials Processing Technology vol. 138, pp. 109-115, 2003.

[8] B. Georgali, P.E. Tsakiridis, Microstructure of fire damaged concrete. A case study, Cement and Concrete Composites, vol. 27(2), pp. 255-259, 2005.

[9] L.I. Lin, W.M. Steen, P.J. Modern and J.T. Spencer, "Laser removal of surface embedded contaminations on/in building structures, Laser Materials Processing and Machining", SPIE: 2246, 1994.

[10] P. Sanjeevan. The effects of geometrical microstructure of cementitious composites on laser cleaning process, $\mathrm{PhD}$ thesis, The School of the Built \& Natural Environment, Glasgow Caledonian University, 2007.

[11] W.T. Chang, C. Wang and C. Huang,"Concrete at temperatures above $1000^{\circ}$ C". Fire Safety Journal vol. 23(3), pp. 223-243, 1994.

[12] M.J.J. Schmidt and L. Li ," Surface modification of OPC- based cent using a frequency doubled Nd:YAG laser system". Applied Surface Science vol. 186, pp. 2002. 